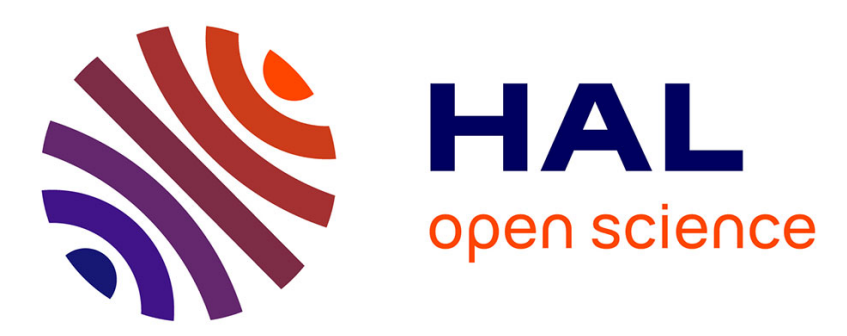

\title{
Transient Gene Expression as a Tool to Monitor and Manipulate the Levels of Acidic Phospholipids in Plant Cells
}

Lise Noack, Přemysl Pejchar, Juraj Sekereš, Yvon Jaillais, Martin Potocky

\section{- To cite this version:}

Lise Noack, Přemysl Pejchar, Juraj Sekereš, Yvon Jaillais, Martin Potocky. Transient Gene Expression as a Tool to Monitor and Manipulate the Levels of Acidic Phospholipids in Plant Cells. Fatima Cvrčková; Viktor Žárský. Plant Cell Morphogenesis. Methods and Protocols, 1992, Springer, pp.189199, 2019, Methods in Molecular Biology, 978-1-4939-9468-7. 10.1007/978-1-4939-9469-4_12 . hal02348954

\section{HAL Id: hal-02348954 \\ https://hal.science/hal-02348954}

Submitted on 6 Nov 2019

HAL is a multi-disciplinary open access archive for the deposit and dissemination of scientific research documents, whether they are published or not. The documents may come from teaching and research institutions in France or abroad, or from public or private research centers.
L'archive ouverte pluridisciplinaire HAL, est destinée au dépôt et à la diffusion de documents scientifiques de niveau recherche, publiés ou non, émanant des établissements d'enseignement et de recherche français ou étrangers, des laboratoires publics ou privés. 


\title{
Transient gene expression as a tool to monitor and manipulate the levels of acidic phospholipids in plant cells
}

Lise C. Noack ${ }^{1}$, Přemysl Pejchar ${ }^{2,3}$, Juraj Sekereš ${ }^{2,3}$, Yvon Jaillais ${ }^{1 *}$, Martin Potocký2,3*

${ }^{1}$ Laboratoire Reproduction et Développement des Plantes, Université de Lyon, ENS de Lyon, UCB Lyon 1, CNRS, INRA, Lyon 69342, France

${ }^{2}$ Institute of Experimental Botany v. v. i.; Academy of Sciences of the Czech Republic; Prague, Czech Republic

${ }^{3}$ Department of Experimental Plant Biology, Faculty of Science, Charles University, Prague, Czech Republic

*Corresponding authors: e-mail: potocky@ueb.cas.cz and yvon.jaillais@ens-lyon.fr

Running head: Exploring phospholipid signalling in plant cells using transient gene expression

\begin{abstract}
Anionic phospholipids represent only minor fraction of cell membranes lipids but they are critically important for many membrane-related processes, including membrane identity, charge, shape, the generation of second messengers and the recruitment of peripheral proteins. The main anionic phospholipids of the plasma membrane are phosphoinositides phosphatidylinositol 4-phosphate (PI4P), phosphatidylinositol 4,5-bisphosphate ( $\left.\mathrm{PI} 4,5 \mathrm{P}_{2}\right)$, phosphatidylserine (PS), and phosphatidic acid (PA). Recent insights in the understanding of the nature of protein-phospholipid interactions enabled the design of genetically-encoded fluorescent molecular probes that can interact with various phospholipids in a specific manner allowing their imaging in live cells. Here, we describe the use of transiently transformed plant cells to study phospholipid-dependent membrane recruitment.
\end{abstract}

Keywords: Microscopy, Nicotiana benthamiana, Nicotiana tabacum, phosphoinositides, phospholipid-binding domains, pollen tube, transient expression 


\section{Introduction}

All living cells are surrounded by membranes, which help to define their spatial identity and create the semipermeable boundary between intra- and extra-cellular space [1]. Typical cellular membrane is composed of a bilayer of lipids and proteins, whose organization and interactions are crucial for its function as organizing platforms for cellular processes. Historically, cellular membrane studies were once dominated by a protein-centric view, where proteins executed majority of membrane-related functions and the membrane lipids were often regarded only as passive players whose role was to provide structural support for bilayer formation [2]. It is now generally accepted that both lipids and proteins play indispensable active roles in the various functions of cellular membranes [3].

Among plant plasma membrane lipids, negatively-charged (anionic) phospholipids, phosphoinositides like phosphatidylinositol 4-phosphate (PI4P) and phosphatidylinositol 4,5-bisphosphate (PI4,5 $\mathrm{P}_{2}$ ), together with phosphatidylserine (PS) and phosphatidic acid (PA), constitute low-abundant but essential component [4-6]. They possess many important roles, which include defining membrane identity, generation of downstream signalling molecules, generating membrane negative charge, modulating membrane curvature and creating binding sites for the targeting of effector proteins [7-12].

The realization of the important roles of anionic phospholipids has created a need for methods that would enable their non-invasive spatio-temporal monitoring in living cells. The identification and characterization of protein modules that specifically bind to various anionic phospholipids led to the idea that these protein modules might be used to detect phospholipids in living cells. This resulted in the development of genetically-encoded phospholipid sensors that consist of the specific phospholipid-binding domains (either single or in tandem) fused with various fluorescent proteins, enabling the live cell imaging of phospholipid dynamics [13-15]. Especially in the past decade, this approach has been successfully used in plants to generate sensors for a wide variety of phospholipids including PI4P [16-18], PI4,5 $\mathrm{P}_{2}[\mathbf{1 7}, \mathbf{1 9}, \mathbf{2 0}]$, PA [21, 22] and PS $[17,22]$. Concomitantly, many enzymes involved in the production and degradation of anionic lipids were identified and the phenotypes of their knockout or overexpressing mutant lines described (for plants see e.g. Refs $\mathbf{2 3}, \mathbf{2 4}$ ). This also led to the development of tools allowing the manipulation of phospholipid levels in the cell upon generic or targeted overexpression of phospholipid-modifying enzymes [25]. 
The recruitment of phospholipid-binding peripheral proteins to cell membranes is essential for many cellular processes. The targeting of proteins to specific phospholipids or to the membranes of particular lipid compositions, mediated by lipid-binding domains, allows their recruitment to be precisely controlled in spatio-temporal fashion. Despite the manifold biological consequences associated with the targeted recruitment of peripheral protein to their target membranes, only a basic understanding of the interactions of proteins with membrane surfaces exists because these questions are inaccessible by commonly used structural techniques [26, 27]. Therefore, the selective colocalization of peripheral proteins (or individual protein domains, protein deletions, point mutations etc.) with the particular lipid marker together with its relocalization after coexpression with corresponding phospholipid-modifying enzymes may bring valuable informations about the nature of protein-membrane interface. Transient gene expression approaches are particularly beneficial, since they enable quick screening of many proteins or protein variants and allow easy manipulation of expression level. Here, we describe the protocols allowing transient coexpression of proteins of interest with genetically-encoded lipid markers or phospholipid-modifying enzymes in two different plant cell types: biolistics-mediated transformation of growing tobacco pollen tubes (that show spatially-separated plasma membrane domains enriched with distinct phospholipids, Refs 21, 22), and agroinfiltration of Nicotiana benthamiana leaf epidermal cells (where high transformation efficiency can be achieved).

\section{Materials}

Prepare all solutions using ultrapure water and store at room temperature (RT), unless stated otherwise.

\subsection{Particle bombardment solutions}

1. Gold particles: resuspend $30 \mathrm{mg}$ of $1.6 \mu \mathrm{m}$ gold microcarriers (Bio-Rad, \#1652264, Note 1) in $1 \mathrm{ml}$ absolute ethanol, vortex vigorously for $3 \mathrm{~min}$ and spin down at table top centrifuge (1 min, maximum speed). Wash twice with $\mathrm{H}_{2} \mathrm{O}$ and resuspend in $1 \mathrm{ml}$ of $50 \%$ glycerol (sterile). Store at $4{ }^{\circ} \mathrm{C}$.

2. $2.5 \mathrm{M} \mathrm{CaCl}_{2}$ : Dissolve $3.675 \mathrm{~g} \mathrm{CaCl}_{2} \cdot 2 \mathrm{H}_{2} \mathrm{O}$ (Sigma, \#C7902) in $10 \mathrm{ml} \mathrm{H}_{2} \mathrm{O}$. Filter sterilize and keep $1 \mathrm{ml}$ aliquots at $-20^{\circ} \mathrm{C}$. Working aliquot can be kept at $4{ }^{\circ} \mathrm{C}$ for several months. 
3. Protamine: Dissolve $10 \mathrm{mg}$ of protamine sulfate (Sigma, \#P4505) in $10 \mathrm{ml} \mathrm{H}_{2} \mathrm{O}$. Filter sterilize and keep $0.5 \mathrm{ml}$ aliquots at $-20{ }^{\circ} \mathrm{C}$. Working aliquot can be kept at $4{ }^{\circ} \mathrm{C}$ for several weeks.

\subsection{DNA}

1. For tobacco pollen particle bombardment, dilute DNA stock with $\mathrm{H}_{2} \mathrm{O}$ to $0.25-1 \mu \mathrm{g} / \mu \mathrm{l}$ working solution. In order to achieve good transformation frequency and expression levels, target construct expression must be driven by promoters active in pollen (typically LAT52p or UBQ10p). 35S promoter is not recommended. Usually, clean miniprep is enough for several transformations. Store at $-20^{\circ} \mathrm{C}$.

2. For $N$. benthamiana leaves infiltration, use DNA plasmid concentrated at $0.25-1 \mu \mathrm{g} / \mu \mathrm{l}$ to transform Agrobacterium. Expression of the construct is usually driven by $U B Q 10$ or $35 S$ promoters.

\subsection{Biological material}

1. Pollen: Flowers of outdoor- or glasshouse-grown tobacco plants (Nicotiana tabacum cv. Samsun) are collected in warm and dry weather conditions before opening; anthers are taken out and kept in laboratory conditions on a filter paper for one day to let anthers open and dehydrate (anthers might be surface sterilized and dried in the laminar box to harvest sterile pollen). Dried pollen grains are sifted through to remove anthers. Harvested pollen can be kept frozen at $-20{ }^{\circ} \mathrm{C}$ without apparent loss of the germination capacity for several years. $1 \mathrm{mg}$ of pollen is usually used per transformation.

2. N. benthamiana leaves: Use tobacco leaves from 2-3 weeks old plants. For infiltration, select leaves that are heart shaped. If the plant has already flowered, it is too late to perform the infiltration.

3. Agrobacterium: The electrocompetent $A$. tumefaciens C58pmp90 strain is used for tobacco leaves infiltration.

\subsection{Cultivation Media}

1. 2x pollen tube medium (2xPTM): $10 \% \mathrm{w} / \mathrm{v}$ sucrose, $25 \% \mathrm{w} / \mathrm{v}$ PEG-6000, $2 \mathrm{mM} \mathrm{CaCl}_{2}, 2$ $\mathrm{mM} \mathrm{KCl}, 1.6 \mathrm{mM} \mathrm{MgSO}_{4}, 3.2 \mathrm{mM} \mathrm{H}_{3} \mathrm{BO}_{3}, 60 \mu \mathrm{M} \mathrm{CuSO}_{4}, 0.06 \%$ w/v casein 
acid-hydrolysate, $0.6 \% \mathrm{w} / \mathrm{v}$ MES, pH 5.9. Prepare 10x stock solution for salts $(1470 \mathrm{mg} / 1$ $\mathrm{CaCl}_{2} \cdot 2 \mathrm{H}_{2} \mathrm{O}, 746 \mathrm{mg} / \mathrm{K} \mathrm{KCl}, 1972 \mathrm{mg} / 1 \mathrm{MgSO}{ }_{4} \cdot 7 \mathrm{H}_{2} \mathrm{O}, 989 \mathrm{mg} / \mathrm{H}_{3} \mathrm{BO}_{3}, 75 \mathrm{mg} / 1 \mathrm{CuSO}_{4} \cdot$ $\left.5 \mathrm{H}_{2} \mathrm{O}\right)$ and $50 \mathrm{x}$ stock for casein hydrolysate $(1.5 \% \mathrm{w} / \mathrm{v})$. Store the stocks at $-20{ }^{\circ} \mathrm{C}$. Dissolve appropriate amounts of sucrose, MES, salt and casein hydrolysate stocks in $\mathrm{H}_{2} \mathrm{O}$, adjust $\mathrm{pH}$ to 5.9 with $4 \mathrm{M} \mathrm{KOH}$, add PEG-6000 and make up to the final volume with $\mathrm{H}_{2} \mathrm{O}$. Store $50 \mathrm{ml}$ aliquots at $-20{ }^{\circ} \mathrm{C}$.

2. Solid pollen tube medium: $1 \times$ PTM solidified with $0.25 \%$ Phytagel (Note 2). Thaw $50 \mathrm{ml}$ aliquot of $2 \mathrm{xPTM}$ and warm it in water bath to at least $60{ }^{\circ} \mathrm{C}$. Prepare $0.5 \%$ Phytagel (Sigma, \#P8169) solution: weigh $0.25 \mathrm{~g}$ of Phytagel into $50 \mathrm{ml} \mathrm{H}_{2} \mathrm{O}$ and resuspend. Dissolve Phytagel by carefully heating up to the boiling point while stirring. Mix 2xPTM and Phytagel solutions and keep the $1 \mathrm{xPTM} / 0.25 \%$ Phytagel medium in hot water bath. In laminar box, prepare plates with solidified medium by rapid pouring of $4 \mathrm{ml}$ of hot PTM/Phytagel solution onto 5 $\mathrm{cm}$ Petri dishes. Let dry and store up to one month at $4{ }^{\circ} \mathrm{C}$.

3. LB medium: Agrobacterium are grown on LB liquid medium (Difco ${ }^{\mathrm{TM}}$ LB Broth, Lennox, \#240230, 20 g/l) and LB plate (Difco ${ }^{\text {TM }}$ LB Broth, Lennox, \#214010, 20 g/1, 15\% w/v agar, Difco $^{\text {TM }}$ Bacto Agar).

4. Infiltration medium: $10 \mathrm{mM}$ MES (Sigma-Aldrich, \#D8250-250G), $10 \mathrm{mM} \mathrm{MgCl}$ (Sigma-Aldrich, \#M2670), 0.15 mM acetosyringone (Sigma-Aldrich, \#D134406). Prepare a stock solution of $100 \mathrm{mM}$ MES. Weight and dissolve the appropriate amount of MES in $\mathrm{H}_{2} \mathrm{O}$ and adjust the $\mathrm{pH}$ to $5.7 \mathrm{using} \mathrm{KOH}$ solution. Autoclave the MES solution for $30 \mathrm{~min}$ and store it at RT. Prepare a stock solution of acetosyringone at $100 \mathrm{mM}$ in EtOH and store it at $-20{ }^{\circ} \mathrm{C}$. Just before performing the infiltration, dilute the MES solution in $\mathrm{H}_{2} \mathrm{O}$, add the $\mathrm{MgCl}_{2}$ and the acetosyringone to a final concentration of $10 \mathrm{mM}$ and $0.15 \mathrm{mM}$, respectively.

\section{Methods}

Carry out all procedures at RT unless otherwise specified (Note 3).

\subsection{DNA macrocarrier preparation for pollen particle bombardment}

Add following to the $1.5 \mathrm{ml}$ microcentrifuge tube to prepare one macrocarrier (the sample should be mixing continuously, keep sequence and timing): $25 \mu 1$ of gold particles suspension, vortex $1 \mathrm{~min}$, add 2.5-7 $\mu$ l of plasmid DNA ( 1-10 $\mu \mathrm{g}$, Note 4), $25 \mu 1$ of $2.5 \mathrm{M}$ 
$\mathrm{CaCl}_{2}$ and $10 \mu \mathrm{l}$ of protamine $(1 \mathrm{mg} / \mathrm{ml})$ solution. Vortex vigorously for at least $3 \mathrm{~min}$. Spin down in tabletop centrifuge for $30 \mathrm{~s}$ at max speed. Remove the supernatant carefully using yellow pipette tip or vacuum and discard it. Resuspend the pellet completely (Note 5) in 200 $\mu l$ of absolute ethanol and vortex for $3 \mathrm{~min}$. Spin down again and discard the supernatant. Resuspend the pellet in $18 \mu \mathrm{l}$ of absolute ethanol, vortex for $1 \mathrm{~min}$ and load the suspension on the macrocarrier (Bio-Rad, \#1652335). Keep the suspension dispersed by constant pipetting. For future manipulations, it is better to have macrocarrier fitted in the steel macrocarrier holder (Bio-Rad, \#1652322) before loading. Let the macrocarrier dry in a vibration-free environment. One should obtain evenly distributed layer of gold particles without any visible clumps. Although dried macrocarriers can be stored in dry chamber at RT for several hours, it is better to perform the transformation immediately after preparation.

\subsection{Pollen plating}

For one transformation, resuspend $1 \mathrm{mg}$ of tobacco pollen per $5 \mathrm{ml}$ of $1 \mathrm{xPTM}$. Pour the suspension on the prewetted nylon $47 \mathrm{~mm}(0.8 \mu \mathrm{m})$ filter disc (Whatman, \#Z746282) placed on filtration apparatus (e.g. Millipore, \#XX1004720) and remove medium using vacuum. Transfer the pollen to the solidified PTM by placing the filter disc upside-down briefly. Repeat for the next DNA sample and/or proceed to the particle bombardment immediately (Note 6).

\subsection{Particle bombardment}

Set up the PDS-1000/He system (Bio-Rad, \#1652257) according to the instruction manual using standard settings. Put the rupture disc (1100 psi, Bio-Rad, \#1652329) in place and tighten gently with the screwdriver. Assemble macrocarrier and stopping screen (Bio-Rad, \#1652336) into microcarrier launch assembly and insert it into the uppermost position. Use the second free slot from above for the pollen plated on solidified medium. Evacuate the chamber to $28 \mathrm{inHg}$ and perform the bombardment. Release the vacuum immediately, seal the sample plate with parafilm and store it at RT.

\subsection{Agrobacterium transformation}

Transform each construct in Agrobacterium. To do so, add $1 \mu 1$ of DNA plasmid into $50 \mu 1$ of electrocompetent Agrobacterium on ice. Transfer the Agrobacterium into cold $1 \mathrm{~mm}$ wide 
electroporation chamber (Eurogentec, \#CE00150). Put the electroporation chamber into the MicropulserTM (Bio-Rad, \#165-2100) and give a pulse of $2 \mathrm{kV}, 335 \Omega, 15 \mu \mathrm{F}$, for $5 \mathrm{~ms}$. Add $1 \mathrm{ml}$ of liquid LB medium and transfer the bacteria into a new tube and incubate them at 29 ${ }^{\circ} \mathrm{C}$ for at least $2 \mathrm{~h}$. Plate the Agrobacterium onto LB plates containing the appropriate antibiotics to select the Agrobacterium strain (gentamycin $20 \mu \mathrm{g} / \mathrm{ml}$ and rifampicin $50 \mu \mathrm{g} / \mathrm{ml}$ ) and the target construct. Incubate the plate at $29^{\circ} \mathrm{C}$ for $48 \mathrm{~h}$.

\subsection{Nicotiana benthamiana infiltration}

Prepare the infiltration medium as indicated in the "cultivation media" part. Scoop transformed Agrobacterium from the transformation plate with a tip and resuspend the bacteria into $2 \mathrm{ml}$ infiltration medium by pipetting. Measure the $\mathrm{OD}_{600}$ using a spectrophotometer (Biophotometer, Eppendorf). Adjust the $\mathrm{OD}_{600}$ to 1 by adding infiltration medium. For co-infiltration of several constructs, mix the same quantity of each transformed Agrobacterium to obtain a final $\mathrm{OD}_{600}$ of 1 . Using $1 \mathrm{ml}$ syringe (Terumo, \#125162229), press the infiltration solution with the Agrobacterium onto the abaxial side of the chosen tobacco leaf keeping your finger on the other side of the leaf. The solution must spread into the leaf (Note 7). Mark the place where the infiltration has been made with a permanent marker. Put the plant back to the growth chamber for 2-3 days.

\subsection{Data acquisition, analyses and quantification}

Images can be exported from the microscope-specific acquisition software and analyzed with suitable analysis software. We use Fiji for this purpose, which is a distribution of well-known software Image $[\mathbf{2 8}, \mathbf{2 9}$ ], bundling a lot of plugins which facilitate scientific image analysis, and which is freely available at https://fiji.sc/. A number of basic and advanced tools are available within this software, including subtraction of background, and measurements of intensities, both based on the definition of a region of interest.

\section{Particle-transformed pollen tubes:}

For the initial evaluation of protein overexpression on pollen tube growth and polarity, observe the cells 12-24 h after transformation with 5-10x lenses. Identify transformed cells based on FP fluorescence and take images using the same acquisition settings. Mean pollen tube length, pollen tube width, tip swelling and cell "curviness" (calculated as the ratio of the 
distance between the pollen grain/pollen tube tip and the pollen tube length, is close to 1 for straight pollen tubes) are good parameters for the initial quantitative assessment.

Several simple measures can be used to monitor the binding of protein of interest to the plasma membrane, e.g. measuring of the membrane- and cytoplasmic-associated intensities from the line scan (Figure 1, see also Refs 21, 30) and calculating the ratio as a proxy for membrane recruitment index, and/or measuring the length of membrane signal (in case of asymmetric localizations, see Figure 1). For the quantitative assessment of colocalization, Pearson or Spearman rank correlation coefficients can be calculated from the data (e.g. with Coloc 2 plugin available in Fiji).

\section{Confocal observation of $N$. benthamiana leaves}

Cut $5 \mathrm{~mm}^{2}$ regions of the leaf that surround the place where the infiltration has been made. Place the piece of leaf into water between slide and coverslip with the abaxial side of the leaf facing the coverslip. It may be convenient to tape the slide and coverslip together to maintain the coverslip on the slide as the leaf sample is thick. Using the appropriate wavelength, an epifluorescent microscope and the smallest objective (10X), screen the surface of the leaf to find the transformed cells. Then, switch to confocal microscope and $63 \mathrm{X}$ objective to look at the subcellular localization of the fluorescent protein.

\section{Analysis of the effect of PM-targeted phosphatases on anionic phospholipid}

\section{localization}

In order to perturb anionic phospholipid production with subcellular accuracy, it is possible to target an isolated phosphatase (or kinase) domain to a specific organelle. For example, Simon et al., targeted the 4-phosphatase SAC domain of the yeast Sac1p protein to the PM using a Myristoylation and Palmitoylation anchor (MP) (see Figure 2). This MP-Sac1 construct was fused to a mTurquoise $2(\mathrm{mTu} 2)$ protein to monitor protein localization (MP-mTu2-Sac1) in order to verify that this synthetic enzyme was indeed efficiently targeted to the PM. Co-transfection with genetically encoded anionic phospholipid sensors allowed to determine the effect of the 4-phosphatase activity on the production of a given phospholipid. Quantification of the effect of the phosphatase activity may be performed using the analyses mentioned above for pollen tubes. Typically, three behaviours may be anticipated for the biosensors following co-expression with an organelle targeted phosphatase: i) no effect, ii) 
redistribution of the sensor from a membrane to a cytosolic pool, and iii) redistribution of the sensor to a different organelle. For example, MP-Sac1 expression induced the redistribution of PI4P biosensors from the PM to endosomes (Figure 2, see also Refs 18, 22, 31). This can be quantified qualitatively, as a percentage of cell with endosomal labelling by the PI4P sensor, as compared to the total number of cells analyzed. It can also be quantified by making a ratio of membrane vs soluble signal, but this later quantification methods is difficult given the reduced cytoplasm of $N$. benthamiana leaf cells. Once validated, such heterologous transient assay may be used to probe the importance of a given lipid for targeting a protein. It may also be used to validate in vivo catalytic activity of a phosphoinositide phosphatase of unknown specificity.

\section{Notes}

1. Different sizes of particles $(0.6$ or $1.0 \mu \mathrm{m})$ may be also used, this will however affect the amount of coatable DNA. Alternatively, cheaper tungsten particles may be used, their size distribution is however much more variable, resulting in yet greater variability in expression levels.

2. Do not use agar or agarose as they would cause the precipitation of pollen tube medium.

3. For the details of PDS-1000/He assembly and operation, consult the PDS-1000/He Particle Delivery System Instruction Manual and watch the YouTube tutorial.

4. When transforming with more than one construct, premix the DNA before coating. Use only small amount (0.5-1 $\mu$ g of plasmids expressing phospholipid markers to prevent the perturbation of phospholipid signalling due to overexpression of lipid-binding domain).

5. This is crucial for obtaining good transformation frequency. The more DNA is added the longer it takes to resuspend the pellet completely.

6. We routinely transform up to 12 plates in a row. If more transformations are needed, split the plating/bombardment into batches of 10 .

7. The infiltration might not work if the stomata are closed. To get around this problem, make small holes with a needle. 


\section{Acknowledgment}

Research in the Prague lab is supported by the Czech Science Foundation (grants no. 17-27477S and and 18-18290J) and by the Ministry of Education Youth and Sport of the Czech Republic (project no. NPUI LO1417). Y.J. is funded by ERC no. 3363360-APPL under FP/2007-2013 and L.C.N is funded by a fellowship from the French Ministry of Higher Education.

\section{References}

1. Bernardino de la Serna, J., Schütz, G.J., Eggeling, C., and Cebecauer, M. (2016). There Is No Simple Model of the Plasma Membrane Organization. Frontiers in Cell and Developmental Biology 4:106.

2. Singer,SJ, and Nicolson GL (1972) The Fluid Mosaic Model of the Structure of Cell Membranes. Science 175:720-731.

3. Nicolson GL (2014). The Fluid-Mosaic Model of Membrane Structure: Still relevant to understanding the structure, function and dynamics of biological membranes after more than 40 years. Biochimica et Biophysica Acta (BBA) - Biomembranes 1838:1451-1466.

4. Devaiah SP, Roth MR, Baughman E, Li M, Tamura P, et al. (2006) Quantitative profiling of polar glycerolipid species from organs of wild-type Arabidopsis and a PHOSPHOLIPASE Da1 knockout mutant. Phytochemistry 67:1907-1924.

5. Mosblech A, König S, Stenzel I, Grzeganek P, Feussner I, et al. (2008) Phosphoinositide and Inositolpolyphosphate Signalling in Defense Responses of Arabidopsis thaliana Challenged by Mechanical Wounding. Molecular Plant 1:249-261.

6. Furt F, Simon-Plas F, Mongrand S (2011) Lipids of the Plant Plasma Membrane. In The Plant Plasma Membrane, A.S. Murphy, B. Schulz, and W. Peer, eds. (Berlin, Heidelberg: Springer Berlin Heidelberg), pp. 3-30.

7. Balla T (2013) Phosphoinositides: Tiny Lipids With Giant Impact on Cell Regulation. Physiological Reviews 93:1019-1137.

8. Kay JG, Grinstein S (2013) Phosphatidylserine-Mediated Cellular Signaling. In Lipid-Mediated Protein Signaling, D. Capelluto, ed. (Springer, Dordrecht), pp. 177-193.

9. Sekereš, J, Pleskot, R, Pejchar, P, Žárský, V, and Potocky, M (2015). The song of lipids and proteins: dynamic lipid-protein interfaces in the regulation of plant cell polarity at different scales. Journal of Experimental Botany 66:1587-1598. 
10. Noack, LC, and Jaillais, Y (2017). Precision targeting by phosphoinositides: how PIs direct endomembrane trafficking in plants. Current Opinion in Plant Biology 40:22-33.

11. Pokotylo, I, Kravets, V, Martinec, J, and Ruelland, E (2018). The phosphatidic acid paradox: Too many actions for one molecule class? Lessons from plants. Progress in Lipid Research 71:43-53.

12. Tanguy, E, Kassas, N, and Vitale, N (2018). Protein-Phospholipid Interaction Motifs: A Focus on Phosphatidic Acid. Biomolecules 8:20.

13. Vermeer, JEM, and Munnik, $T$ (2010). Imaging Lipids in Living Plants. In Lipid Signaling in Plants, T. Munnik, ed. (Berlin, Heidelberg: Springer Berlin Heidelberg), pp. 185-199.

14. Platre, MP, and Jaillais, Y (2016). Guidelines for the Use of Protein Domains in Acidic Phospholipid Imaging. In Lipid Signaling Protocols, M.G. Waugh, ed. (New York, NY: Springer New York), pp. 175-194.

15. Várnai, P, Gulyás, G, Tóth, DJ, Sohn, M, Sengupta, N, et al. (2017). Quantifying lipid changes in various membrane compartments using lipid binding protein domains. Cell Calcium 64:72-82.

16. Vermeer, JEM, Thole, JM, Goedhart, J, Nielsen, E, Munnik, T, et al. (2009). Imaging phosphatidylinositol 4-phosphate dynamics in living plant cells. The Plant Journal $57: 356-372$.

17. Simon, MLA, Platre, MP, Assil, S, van Wijk, R, Chen, WY, et al. (2014). A multi-colour/multi-affinity marker set to visualize phosphoinositide dynamics in Arabidopsis. The Plant Journal 77:322-337.

18. Simon, MLA, Platre, MP, Marquès-Bueno, MM, Armengot, L, Stanislas, T, et al. (2016). A PtdIns(4)P-driven electrostatic field controls cell membrane identity and signalling in plants. Nature Plants 2:16089.

19. Kost, B, Lemichez, E, Spielhofer, P, Hong, Y, Tolias, K, et al. (1999). Rac Homologues and Compartmentalized Phosphatidylinositol 4, 5-Bisphosphate Act in a Common Pathway to Regulate Polar Pollen Tube Growth. The Journal of Cell Biology 145:317-330.

20. van Leeuwen, W, Vermeer, JEM, Gadella, TWJ, and Munnik, T (2007). Visualization of phosphatidylinositol 4,5-bisphosphate in the plasma membrane of suspension-cultured tobacco BY-2 cells and whole Arabidopsis seedlings. The Plant Journal 52:1014-1026.

21. Potocký, M, Pleskot, R, Pejchar, P, Vitale, N, Kost, B, et al. (2014). Live-cell imaging of phosphatidic acid dynamics in pollen tubes visualized by Spo20p-derived biosensor. New Phytologist 203:483-494. 
22. Platre, MP, Noack, LC, Doumane, M, Bayle, V, Simon, MLA, et al. (2018). A Combinatorial Lipid Code Shapes the Electrostatic Landscape of Plant Endomembranes. Developmental Cell 45:465-480.

23. Heilmann, I (2016). Phosphoinositide signaling in plant development. Development 143:2044-2055.

24. Yao, H-Y, and Xue, H-W (2018) Phosphatidic acid (PA) plays key roles regulating plant development and stress responses. Journal of Integrative Plant Biology in press, doi:10.1111/jipb. 12655

25. Idevall-Hagren, O, and De Camilli, P (2015). Detection and manipulation of phosphoinositides. Biochimica et Biophysica Acta (BBA) - Molecular and Cell Biology of Lipids 1851:736-745.

26. Pu, M., Orr, A., Redfield, A.G., and Roberts, M.F. (2010). Defining Specific Lipid Binding Sites for a Peripheral Membrane Protein in Situ Using Subtesla Field-cycling NMR. Journal of Biological Chemistry 285, 26916-26922.

27. Pleskot, R., Cwiklik, L., Jungwirth, P., Žárský, V., and Potocký, M. (2015). Membrane targeting of the yeast exocyst complex. Biochimica et Biophysica Acta (BBA) Biomembranes 1848, 1481-1489.

28. Schindelin, J, Arganda-Carreras, I, Frise, E, Kaynig, V, Longair, M, et al. (2012). Fiji: an open-source platform for biological-image analysis. Nature Methods 9:676-682.

29. Schneider, CA, Rasband, WS, and Eliceiri, KW (2012). NIH Image to ImageJ: 25 years of image analysis. Nature Methods 9:671-675.

30. Sekereš, J, Pejchar, P, Šantrůček, J, Vukašinović, N, Žárský, V, et al. (2017). Analysis of Exocyst Subunit EXO70 Family Reveals Distinct Membrane Polar Domains in Tobacco Pollen Tubes. Plant Physiology 173:1659-1675.

31. Gronnier, J., Crowet, J.-M., Habenstein, B., Nasir, M.N., Bayle, V., et al. (2017). Structural basis for plant plasma membrane protein dynamics and organization into functional nanodomains. eLife, e26404. 


\section{Figure legends}

Figure 1. Elevation of PI4,5 $\mathrm{P}_{2}$ levels by the overexpression of the CFP-tagged PI4P-5 kinase (PI4P5K) results in increased NtSEC3a:YFP recruitment to the plasma membrane in tobacco pollen tubes. Pollen tubes with comparably low expression level of NtSEC3a:YFP were selected. For co-expression with PI4P5K, cells expressing high levels of PI4P5K:CFP (not shown) and displaying characteristic PI4PK5-overexpression phenotype were selected. White dashed lines mark the site of intensity profiles and yellow dotted lines indicate length of the membrane fluorescence signal. Micrographs are shown using a color intensity code in order to display local enrichment of the YFP fluorescence. See Sekereš et al. (2017) for more details.

Figure 2. Organelle-targeted phosphatase as a way to locally interfere with acidic phospholipids. a) The top panel represents a schematic representation of a possible construct for organelle-specific targeting of a lipid modifying enzyme. Such system include an organelle-specific targeting anchor/protein (which may be at the $\mathrm{N}$ - or C-terminal end of the synthetic chimeric protein), a fluorescent protein to verify localization specificity, and the isolated catalytic domain of a lipid modifying enzyme. An important criteria for the use of the catalytic domain is that it should be free of any endogenous targeting capacity. The bottom panel represent an example of construct for the specific depletion of PI4P at the plasma membrane (i.e. MP-Sac1). b) Schematic representation of MP-Sac1 action at the PM but not endosome and c) effect of MP-Sac1 on PI4P accumulation. In the control condition (left, for example with expression of a catalytically dead MP-Sac1 enzyme), there is much more PI4P at the PM than in endosomes and as a result, a PI4P biosensor such as P4M is localized preferentially at the PM. Upon expression of MP-Sac1 (right), the pool of PI4P at the PM is reduced, which triggers the redistribution of the P4M PI4P sensor to both PM and endosomes. 
Figure 1.
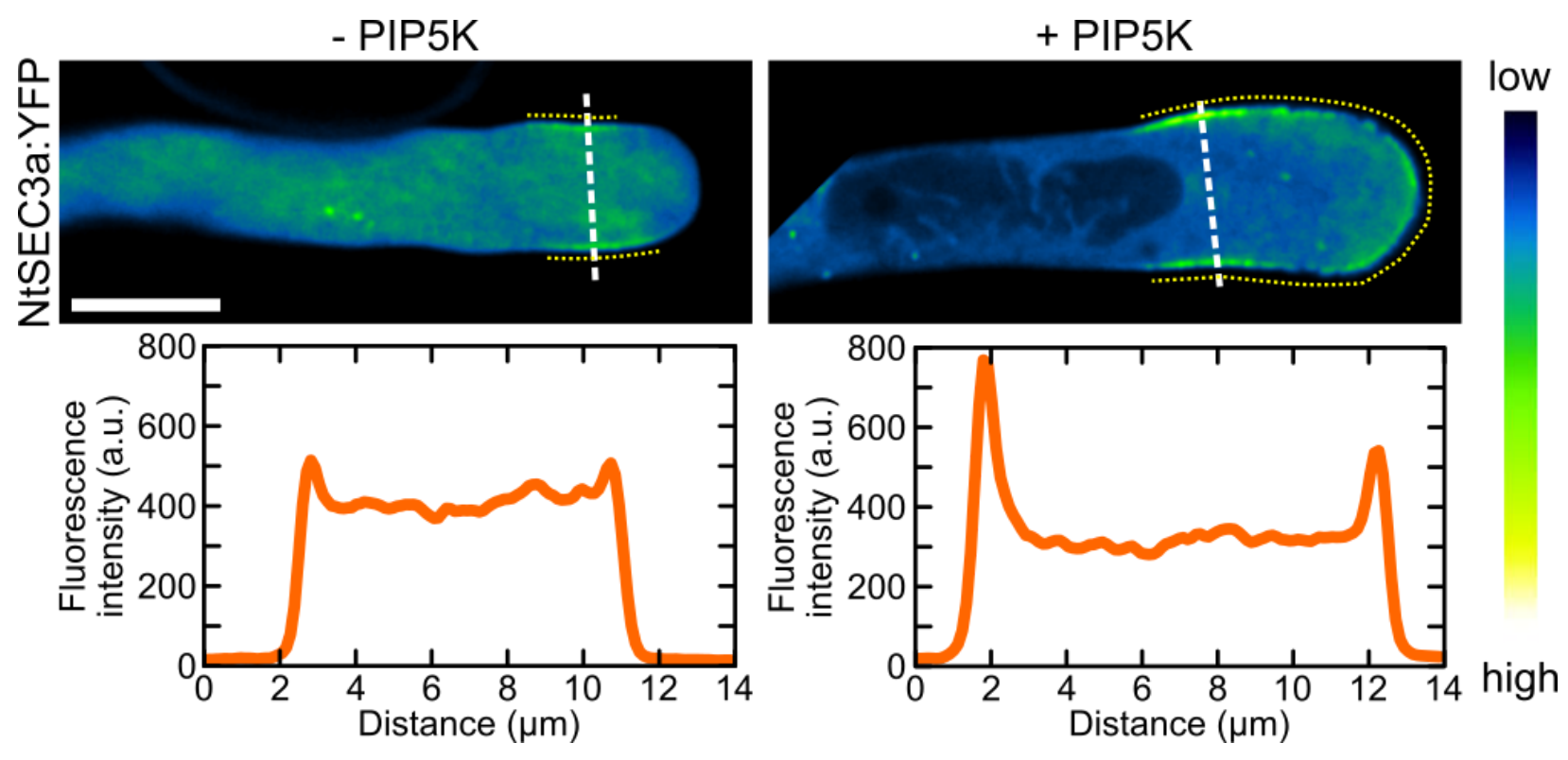

Figure 2

a

targeting FP enzyme (catalytic domain)

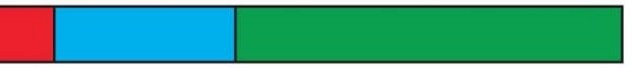

example: plasma membrane taregted 4-phosphatase

\begin{tabular}{|l|l|l|}
\hline MP & mTu2 & Sac1 $p^{\text {cat }}$ \\
\hline
\end{tabular}

b
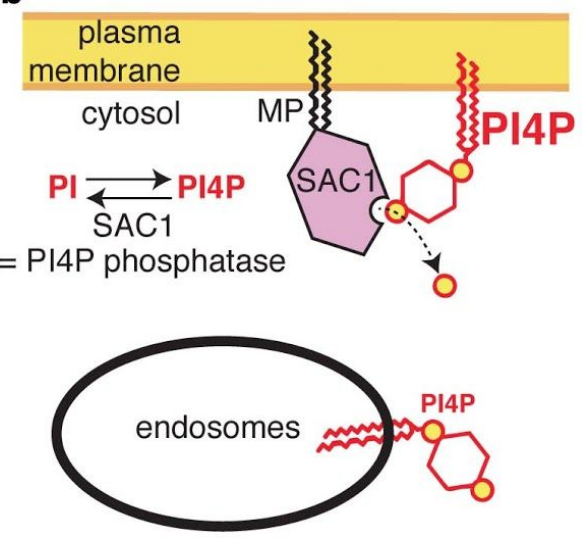

C
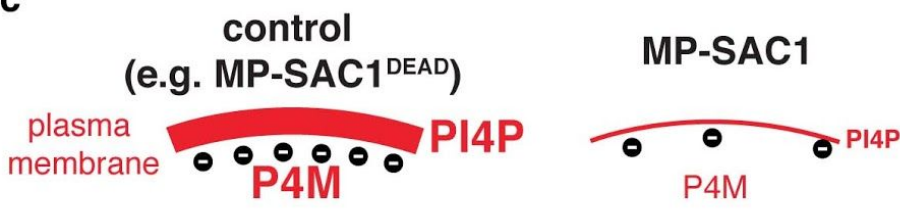

endo-

membranes

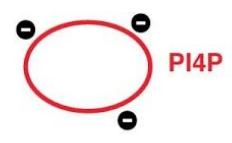

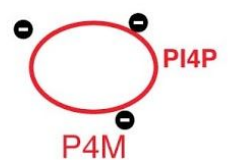

